\title{
Effect of oxidants and anionic surfactants on the morphology and permittivity of polypyrrole and its blends with epoxy resin
}

\author{
Regiane Aparecida Medeiros Campos ${ }^{1 *}$, Valdirene Aparecida da Silva ${ }^{1}$, Roselena Faez ${ }^{2}$ \\ and Mirabel Cerqueira Rezende ${ }^{1,3}$
}

\author{
'Instituto Tecnológico de Aeronáutica - ITA, São José dos Campos, SP, Brazil \\ 'Laboratório de Materiais Poliméricos e Biossorventes, Universidade Federal de São Carlos - UFSCar, \\ Araras, SP, Brazil \\ ${ }^{3}$ Instituto de Ciência e Tecnologia, Universidade Federal de São Paulo - UNIFESP, \\ São José dos Campos, SP, Brazil \\ *remedeiroscampos@gmail.com
}

\begin{abstract}
In this work, conductive polymers were prepared based on polypyrrole (PPy) and its blends with epoxy resin. The chemical syntheses of PPy used two oxidants $\left(\mathrm{Fe}_{2}\left(\mathrm{SO}_{4}\right)_{3}\right.$ and $\left.\mathrm{FeCl}_{3} \cdot 6 \mathrm{H}_{2} \mathrm{O}\right)$ and two surfactants (DBSNa and DBSA). PPy samples and their blends were characterized by scanning electron microscopy, electrical conductivity by four points, and measurements of complex parameters of electric permittivity $(\varepsilon)$ and magnetic permeability, in the frequency range of 8.2 to $12.4 \mathrm{GHz}$. The micrographs of the fractured surfaces show that the PPy synthetized in the presence of surfactants has particles with smaller diameters, and the oxidant sulfate favored the formation of elongated structures, called fillets. The analysis of the blends found a homogeneous distribution of PPy clusters in epoxy resin matrix, which did not favor the electrical conductivity of these materials. On the other hand, the measurements of the complex parameters of the permittivity show that the blends have increasing values when the PPy concentration is increased in the epoxy resin.
\end{abstract}

Keywords: polypyrrole, anionic surfactants, permittivity, blends.

\section{Introduction}

A wide range of polymers is currently available for various purposes. Generally, polymers have been extensively used due to their advantages over other materials such as good mechanical strength, flexibility, environmental stability, low production cost, low density, electrical isolation, and ease processing and shaping. The possibility to associate most of the characteristics of this material class with the property of electrical conductivity has aroused much interest. Hence, the study of conductive polymers has become a widely investigated challenge ${ }^{[1]}$.

The achievement of doped polyacetylene in $1977^{[2]}$ and accounts of its intrinsic electrical conductivity (in order of magnitude of some metals at room temperature) started a new area of interest in the Intrinsically Conducting Polymers (ICPs). The chemistry of ICPs offers a variety of synthetic methods. The possibility of their incorporation into different types of matrices has been evaluated to meet different requirements of the final application. Thus, the preparation of blends with ICPs has been increasingly studied, so that the interchain and intrachain electron transfer of ICPs is ensured.

Polypyrrole (PPy), along with polyaniline, is one of the most promising conducting polymers due to its excellent chemical stability, ease of synthesis, high electrical conductivity, and electronic properties. The PPy began to receive greater attention after 1979, when Diaz et al..$^{[3]}$ obtained a black film of PPy from the electrolysis of a pyrrole solution in acetonitrile and tetramethylammonium tetrafluoroborate. In addition to obtaining high electrical conductivity $\left(100 \mathrm{~S} . \mathrm{cm}^{-1}\right)$, these authors reported that the material can be cycled repeatedly between conductive oxidized and reduced insulator states, showing a redox process between the polymer chain and dopant agent.

Blends of a conventional polymer (insulator) and an ICP can be prepared by various techniques, such as evaporation of the solution containing the mixture of components, polymerization of the conductive polymer in the presence of a conventional polymer matrix, chemical and electrochemical routes ${ }^{[4]}$, or by mechanical blending, for example, in extruders ${ }^{[5]}$. This material class has been extensively studied and used in different areas, such as electromagnetic interference shields, sensors, static charge dissipation, and electromagnetic radiation absorbers ${ }^{[6-14]}$.

Preparing blends of insulating polymers with ICPs in order to obtain radar absorbing materials (RAM), also called microwave absorbers, has as important data the electric conductivity and the complex parameters of electric permittivity of the material ${ }^{[3,6,13,15,16]}$. These parameters are affected by the polymer chain size, doping level, dopant type, synthesis method, and procedure used to prepare the blends ${ }^{[16]}$. Therefore, very strict control of experimental parameters is necessary. Especially in the case of a mixture, it is essential to understand the behavior of the formed phases, because these may modify the final properties of the material. 
Hence, the objective of this study is to correlate the morphological aspects of the synthesized polypyrrole in different chemical environments, using two oxidants (ferric sulfate and ferric chloride) and two surfactants (sodium dodecylbenzenesulphonate and dodecylbenzenesulfonic acid) and its blends with epoxy resin, with complex parameters of electric permittivity.

\section{Experimental}

\subsection{PPy synthesis and their blends}

The chemical synthesis of PPy was performed using two different routes. The first was done with two different oxidants, ferric sulfate $\left(\mathrm{Fe}_{2}\left(\mathrm{SO}_{4}\right)_{3}\right)$ and ferric chloride hexahydrate $\left(\mathrm{FeCl}_{3} \cdot 6 \mathrm{H}_{2} \mathrm{O}\right)$, both from Vetec $\mathrm{Pa}$. The second route used the same oxidants but added two different surfactants, sodium dodecylbenzenesulphonate (DBSNa) and dodecylbenzenesulfonic acid, (DBSA), both from Fluka, with $90 \%$ purity, as previously described by the authors ${ }^{[10]}$.

The first route used a $0.05 \mathrm{~mol}$ solution of pyrrole in $50 \mathrm{~mL}$ of distilled water, added drop by drop to the two oxidizing solutions containing $0.1 \mathrm{~mol}^{\circ} \mathrm{FeCl}_{3}$ and $0.05 \mathrm{~mol}$ of $\mathrm{Fe}_{2}\left(\mathrm{SO}_{4}\right)_{3}$, respectively. The reactions were constantly stirred for $4 \mathrm{~h}$ at room temperature. The obtained black precipitate of PPy was filtered, washed with distilled water, and dried in a vacuum oven at $50{ }^{\circ} \mathrm{C}$ for $16 \mathrm{~h}$.

The second route of PPy synthesis was done in the presence of DBSNa and DBSA surfactants. Solutions containing $0.05 \mathrm{~mol}$ of $\mathrm{FeCl}_{3}$ and $0.025 \mathrm{~mol}$ of $\mathrm{Fe}_{2}\left(\mathrm{SO}_{4}\right)_{3}$ were prepared in $50 \mathrm{~mL}$ of distilled water. Separately, $50 \mathrm{~mL}$ of aqueous solutions with $0.05 \mathrm{~mol}$ of DBSNa and DBSA were prepared, respectively. The solutions with the oxidants and surfactants were mixed and constantly stirred for $15 \mathrm{~min}$. Then, $0.08 \mathrm{~mol}$ of pyrrole was transferred into $25 \mathrm{~mL}$ of distilled water and added drop by drop to the oxidant/surfactant solution by stirring for $4 \mathrm{~h}$. The PPi obtained was filtered, washed, and dried in a vacuum oven for $16 \mathrm{~h}$.

The PPy/epoxy resin blends were obtained by varying the ratio of PPy in 1,10 , and $20 \%(\mathrm{w} / \mathrm{w})$ in $4.0 \mathrm{~g}$ of an Araldite $^{\circledR}$ professional type epoxy resin, commercially available. The homogenized mixtures were manually poured into aluminum molds with a thickness of $4.0 \mathrm{~mm}$. The curing of the epoxy resin occurred at around $60^{\circ} \mathrm{C}$ in an oven for $24 \mathrm{~h}$.

\subsection{Characterization}

Samples of PPy and its blends with epoxy resin were characterized by scanning electron microscopy (SEM), in a LEO equipment, model 435 Vip, using cryogenic fracture surfaces, metalized with gold.

Electrical conductivity measurements of the blends were performed using the 4 tip method ${ }^{[17]}$, with $1.27 \mathrm{~mm}$ distance between the tips, as presented in a previous study ${ }^{[10]}$. Measurements were performed in triplicate with an equipment from Cascade Microtech C4s-64 coupled to a Keithley 236 source, a multimeter and an ammeter, using $13 \mathrm{~mm}$ diameter and $1 \mathrm{~mm}$ thick samples.

The parameters of complex permittivity ( $\varepsilon$ '- real component, related to the storage; and $\varepsilon$ "- imaginary component - related to losses) and magnetic permeability
( $\mu$ ' and $\mu$ '- real and imaginary components, respectively) of samples were evaluated using an vector network analyzer HP $8510 C$, adapted with a rectangular waveguide in the frequency band from 8.2 to $12.4 \mathrm{GHz}$. Sample sizes were equal to $22.86 \mathrm{~mm} \times 10.30 \mathrm{~mm} \times 9.0 \mathrm{~mm}$. The Nicolson-Ross model was used to calculate $\varepsilon$, and $\mu^{[18-20]}$.

\section{Results and Discussion}

Scanning electron microscopy was used to evaluate the morphology of the synthesized samples of PPy and its blends with epoxy resin, for the effect of the oxidants and surfactants used. The morphologies of the fracture surfaces of PPy samples without addition of surfactant (PPy-SO and $\mathrm{PPy}-\mathrm{Cl}$, respectively) are shown in Figure 1. These micrographs illustrate the formation of clusters of globular particles of about $1 \mu \mathrm{m}$. The micrographs of samples prepared with the addition of the surfactant show more compact morphology. In the sample of $\mathrm{PPy}-\mathrm{SO}_{4}$-DBSNa, for example, there is a deformation and decrease of particles, with the initial formation of thin, elongated structures, called fillets in this study. For the sample of PPy-Cl-DBSNa (with the same surfactant), the behavior is similar, but with a more compact structure without the formation of fillets.

The PPy-SO $\mathrm{SO}_{4}$-DBSA sample presents a more distinct morphology, with the formation of both grains and larger fillets. The sample of PPy-Cl-DBSA has clusters of particles, but no formation of fillets as in the samples prepared with $\mathrm{Fe}_{2}\left(\mathrm{SO}_{4}\right)_{3}$.

The elongated structures, called fillets in this study, which are found in the samples synthesized in the presence of sulfate and the two surfactants (PPy-SO $-\mathrm{SO}_{4} \mathrm{DBSA}$ and $\mathrm{PPy}-\mathrm{SO}_{4}$ DBSNa), are attributed to the formation of cylindrical micelle, as shown in Figure 2. However, the samples obtained with the oxidant chloride are characterized by the formation of spherical micelles. This behavior is attributed to the larger volume of oxidant sulfate, which when combined with the surfactant induces the formation of thermodynamically more stable structures through the nucleation of cylindrical micelles ${ }^{[21-24]}$. In the case of DBSNa, the increased volume of this surfactant molecule is favored by the formation of more robust fillets.

Correlation of the observations made by SEM with electrical conductivity data previously published by the authors for these same samples ${ }^{[10]}$ allows to infer that the fillets increase electrical conductivity values $\left(8.9\right.$ and $13 \mathrm{~S} . c m^{-1}$ for the $\mathrm{PPy}-\mathrm{SO}_{4}-\mathrm{DBSNa}$ and $\mathrm{PPy}-\mathrm{SO}_{4}$-DBSA polymers, respectively). This suggests that this type of structure is formed by more linear polymer chains, which favors the conduction of electrons.

Figure 3 illustrates aspects observed in cluster-rich regions in the blends processed by mixing the six different synthesized PPy polymers (PPy-Cl, $\mathrm{PPy}-\mathrm{SO}_{4}, \mathrm{PPy}-\mathrm{Cl}-\mathrm{DBSNa}$, PPy-Cl-DBSA, PPy-SO - -DBSNa, and PPy-SO - -DBSA) in epoxy resin at a percentage of $1 \%(\mathrm{wt} / \mathrm{wt})$. The analysis of the regions containing the clusters shows that the interaction between the two components of the PPy/epoxy resin blend is good, without the presence of loose particles, and forms smooth resin regions. These aspects are very clear in the micrograph of the $\mathrm{PPy}_{-} \mathrm{SO}_{4}$-DBSA sample, which highlights 


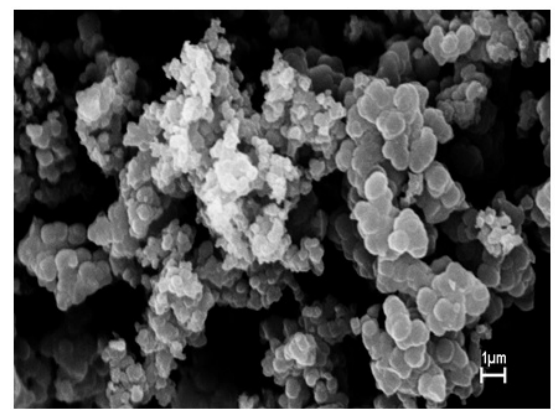

PPy-Cl

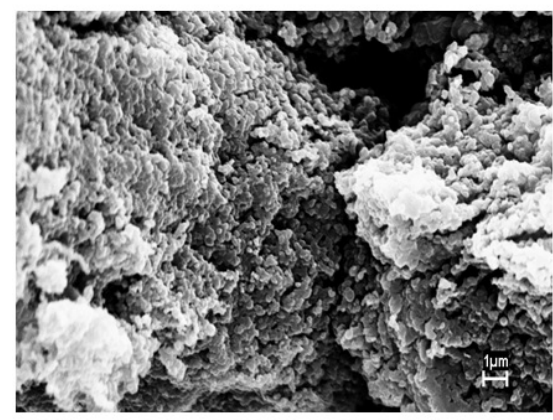

PPy-Cl-DBSNa

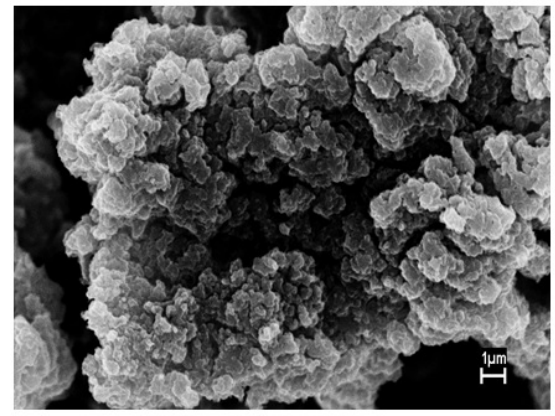

PPy-Cl-DBSA
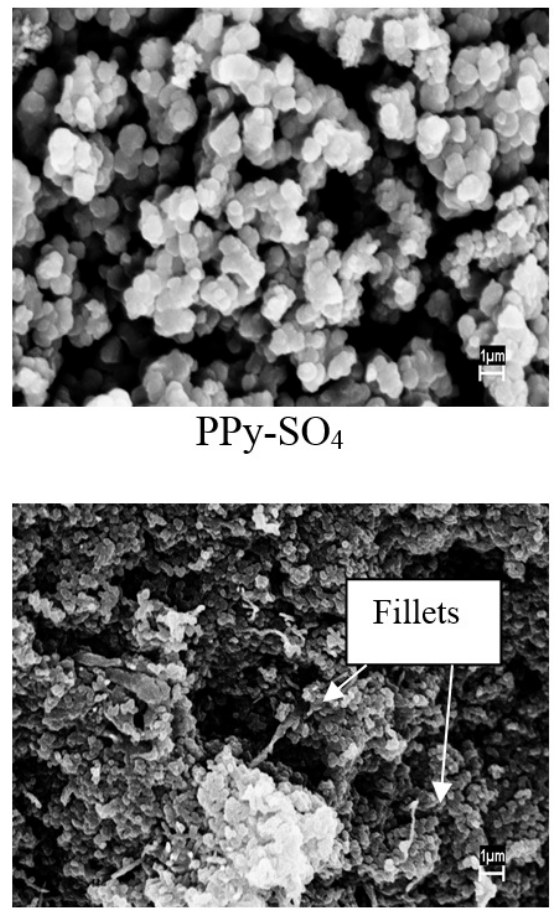

PPy-SO 4 -DBSNa

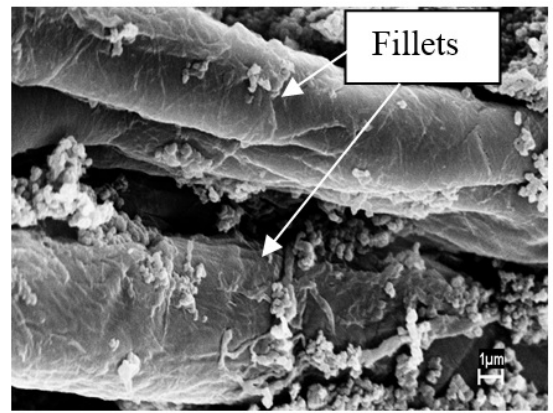

$\mathrm{PPy}-\mathrm{SO}_{4}$-DBSA

Figure 1. SEM of PPy samples with different oxidants and surfactants (5000x).
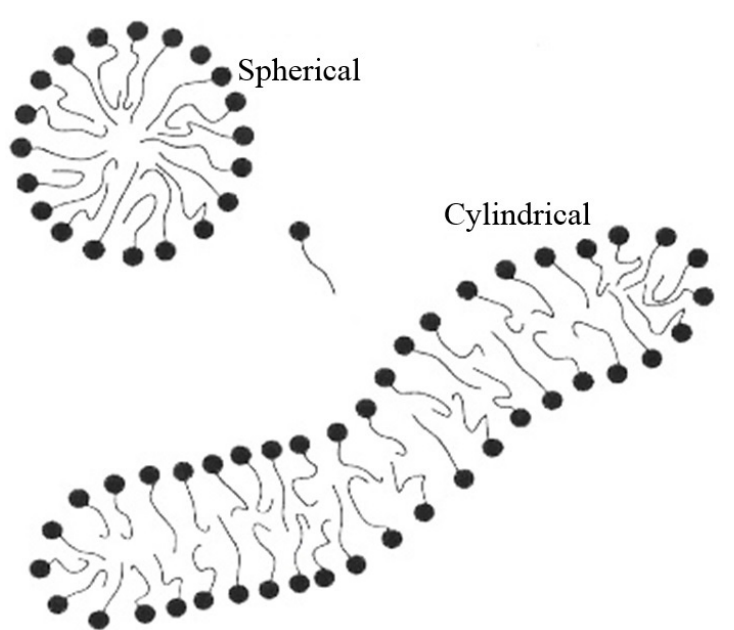

Figure 2. Schematic representation of spherical and cylindrical micelles $^{[21]}$. the fillets covered by the epoxy resin matrix. The samples obtained with the chlorinated oxidant (PPy-Cl-DBSNa and PPy-Cl-DBSA) show the globular particles of the PPy matrix.

Despite the good interaction of PPy polymers in epoxy resin matrix, the smaller magnifications show that the obtained blends are formed primarily of PPy agglomerates homogeneously distributed in the epoxy resin matrix. The blends with $1 \%$ (wt/wt) of PPy have extensive smooth regions of epoxy resin, which are typical of fractured surfaces of fragile materials found in thermoset matrices.

Figures 4 and 5 show the morphological characteristics of the blends obtained by incorporating 10 and 20\% (wt/wt) of PPy into the epoxy resin, respectively. These images shows that the increased concentration of the PPy in the blends creates a more brittle material, as illustrated in Figure 4 for samples $\mathrm{PPy}-\mathrm{SO}_{4}-10 \%$ /epoxy resin and $\mathrm{PPy} \mathrm{SO}_{4}$-DBSNa-10\%/epoxy resin as well as in Figure 5 for the sample PPy-Cl-DBSNa-20\%/epoxy resin. The brittle aspect is observed by the presence of regions with loose plates. 


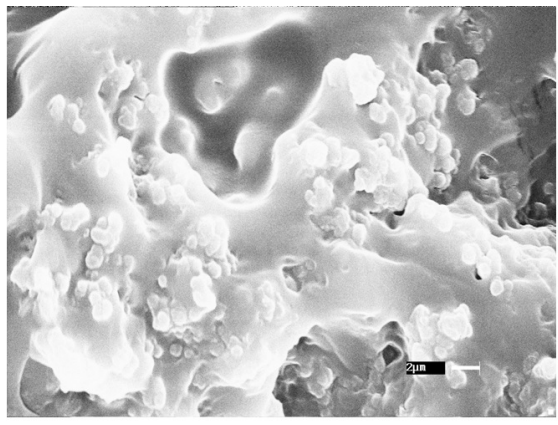

$\mathrm{PPy}-\mathrm{Cl}$

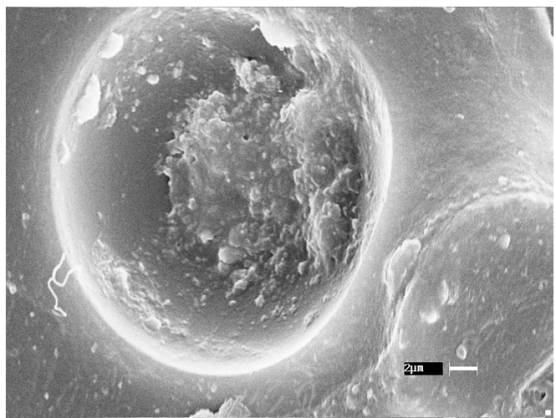

PPy-Cl-DBSNa

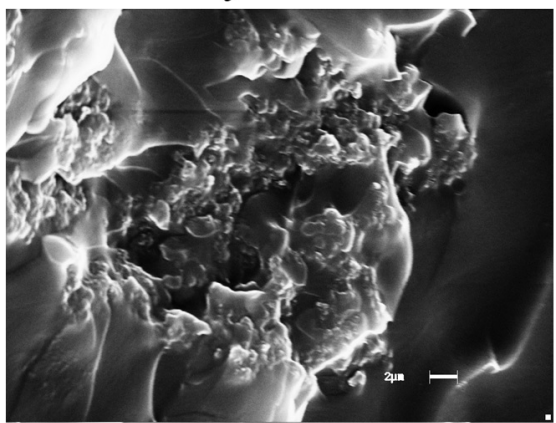

PPy-Cl-DBSA

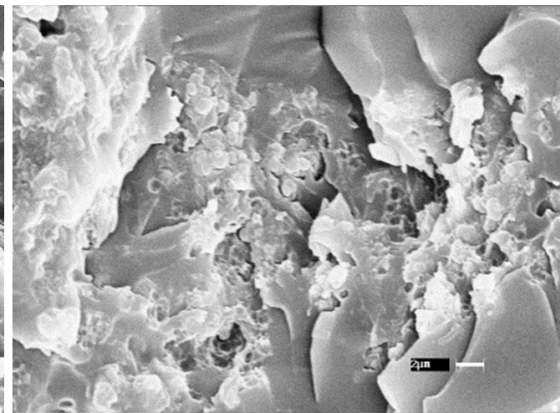

$\mathrm{PPy}_{-} \mathrm{SO}_{4}$

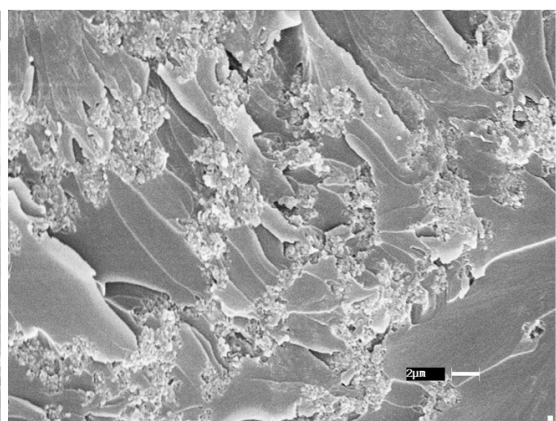

$\mathrm{PPy}-\mathrm{SO}_{4}-\mathrm{DBSNa}$

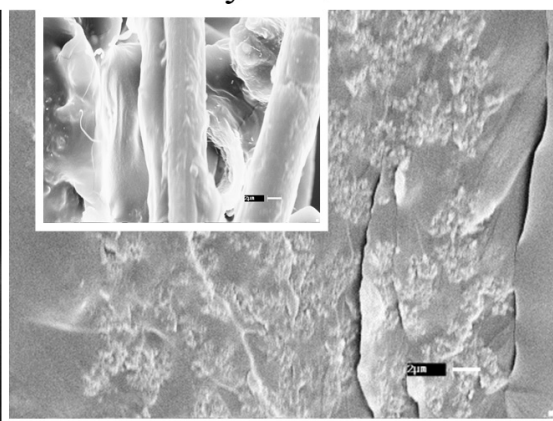

$\mathrm{PPy}_{-} \mathrm{SO}_{4}-\mathrm{DBSA}$

Figure 3. SEM of the blends containing 1\% (wt/wt) of PPy in epoxy resin (3000x).

However, all the prepared samples present good interaction of the components. Blends with increased concentration of conductive polymer with 10 and $20 \%$ (wt/wt) of PPy did not display the fillet structures, suggesting that these were well incorporated into the epoxy resin.

The electrical conductivity measurements of all blends show insulating behavior. This indicates that the percolation threshold was not met because the PPy formed agglomerates into the epoxy resin matrix or that the PPy was undoped during the preparation of the blend with the epoxy resin. Despite this behavior, the literature ${ }^{[10]}$ shows that some of the same blends studied in this work behave as radar absorbing material and show a good interaction with the electromagnetic wave, attenuating up to $95 \%$ of the incident radiation. In this case, one must consider that the mechanisms of loss that occur in the dielectric absorbers, such as those studied in this work, can occur through ohmic losses and/or dielectric losses, Equation $1^{[25-27]}$. In such cases, the total electrical conductivity $\left(\sigma_{\mathrm{T}}\right)$ comprises a static component
( $\sigma$ - electrical conductivity) and a dynamic component ( $\omega \varepsilon ")$ (Equation 1), where the complex electric permittivity $(\varepsilon)$ of a material is defined according to Equation $2^{[25,26]}$.

$$
\begin{aligned}
& \sigma_{\mathrm{T}}=\sigma+\omega \varepsilon^{\prime \prime} \\
& \varepsilon=\varepsilon^{\prime}-j \varepsilon^{\prime \prime}
\end{aligned}
$$

where: $\omega$ is the angular frequency; $\varepsilon$ ' - is the real part of electric permittivity, related to the storage component; and $\varepsilon "$ - is the imaginary part of electric permittivity, related to the loss component.

From the insulating behavior observed in electrical conductivity $(\sigma)$ measurements of the studied blends, the variation of complex parameters $\varepsilon$ and $\mu$ of these materials was investigated. Figure 6 shows the curves of real and imaginary components of the electric permittivity and magnetic permeability of the used epoxy resin. The blends containing $1 \%(\mathrm{wt} / \mathrm{wt})$ of PPy in epoxy resin had values of 


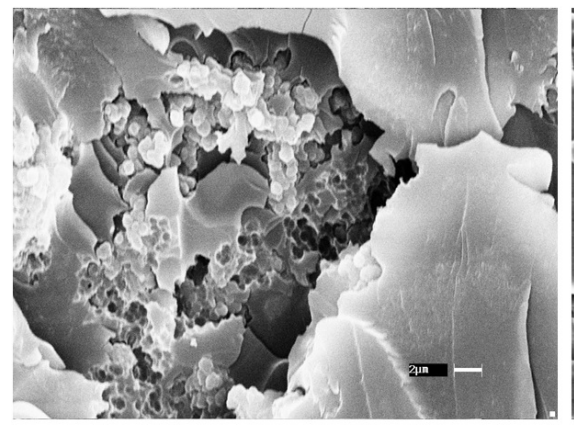

$\mathrm{PPy}-\mathrm{Cl}$

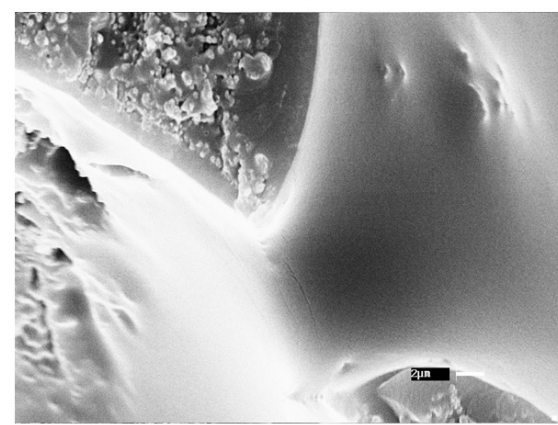

PPy-Cl-DBSNa

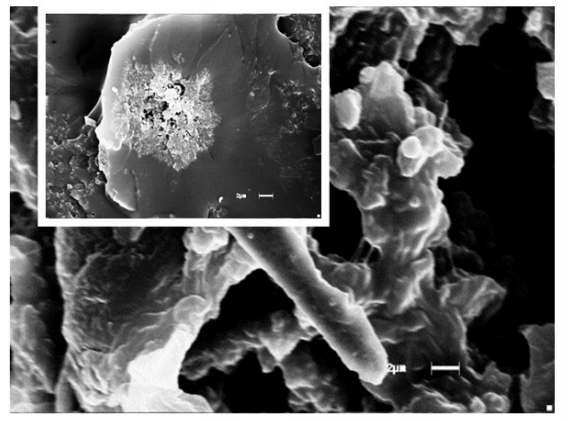

PPy-Cl-DBSA

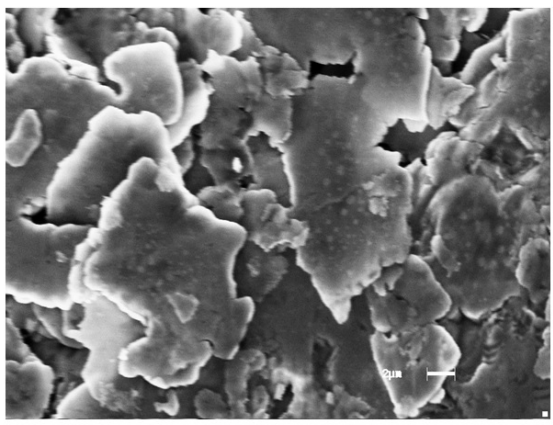

$\mathrm{PPy}_{-} \mathrm{SO}_{4}$

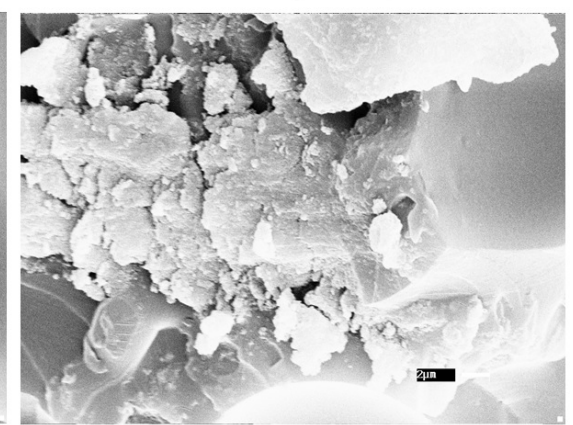

$\mathrm{PPy}-\mathrm{SO}_{4}-\mathrm{DBSNa}$

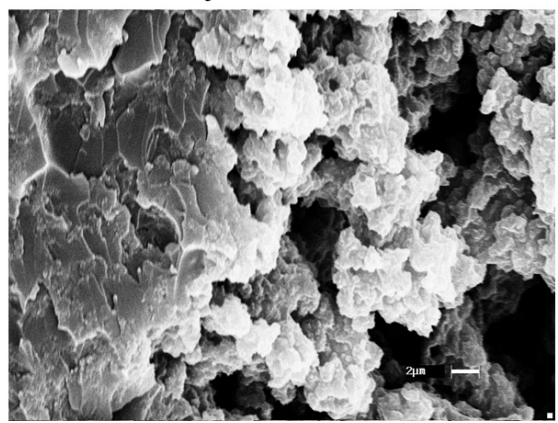

$\mathrm{PP}_{\mathrm{y}}-\mathrm{SO}_{4}-\mathrm{DBSA}$

Figure 4. SEM of the blends with $10 \%$ (wt/wt) of PPy in epoxy resin (3000x).

real and imaginary components of electric permittivity very similar for all the six blends prepared. This result shows that this concentration $(1 \% \mathrm{wt} / \mathrm{wt})$ is too low to change the complex parameters of epoxy resin matrix.

The complex parameters show a slight variation with the frequency, with the tendency to decrease with increasing frequency ${ }^{[25,26]}$. However, in the rated frequency range $(8.2$ to $12.4 \mathrm{GHz})$ and the ordered scale used, Figure 6 shows that the complex parameters of epoxy resin varied only a little with increasing frequency. Table 1 shows these values at a frequency of $10 \mathrm{GHz}$. Figure 6 also shows that the curves of $\mu^{\prime}$ and $\mu$ " are around 1 and 0 , respectively. These values were expected and are typical of dielectric materials $^{[19,26]}$.

Figures 7 and 8 show curves of the real and imaginary components of electric permittivity and magnetic permeability of the blends containing 10 and $20 \%(\mathrm{wt} / \mathrm{wt})$ of PPy, respectively. Tables 1 and 2 summarize the values of the
Table 1. Values of complex parameters of electric permittivity of epoxy resin and the blends with $10 \%$ (wt $/ \mathrm{wt}$ ) of PPy, at $10 \mathrm{GHz}$.

\begin{tabular}{lcc}
\hline \multicolumn{1}{c}{ Sample } & $\boldsymbol{\varepsilon}^{\prime}$ & $\boldsymbol{\varepsilon}^{\prime \prime}$ \\
\hline Epoxy resin & 2.7506 & 0.0941 \\
PPy-Cl-10\%/epoxy resin & 4.0444 & 0.8669 \\
PPy-Cl-DBSA10\%/epoxy resin & 2.7039 & 0.1585 \\
PPy-Cl-DBSNa10\%/epoxy resin & 4.1252 & 0.7789 \\
PPy-SO $-10 \% /$ epoxy resin & 3.1343 & 0.2961 \\
PPy-SO $_{4}$-DBSA10\%/epoxy resin & 3.2082 & 0.3974 \\
PPy-SO - DBSNa10\%/epoxy resin & 3.3097 & 0.3935 \\
\hline
\end{tabular}

complex electric permittivity, at $10 \mathrm{GHz}$, of blends containing 10 and 20\% (wt/wt) of PPy, respectively.

Contrary to that observed for the epoxy resin and its blends with $1 \%$ (wt/wt) of PPy, Figures 7 and 8 show that the blends with 10 and $20 \%$ (wt/wt) of PPy have significant variations of complex parameters of $\varepsilon$. In this case, greater concentration of PPy in epoxy resin increased the values 

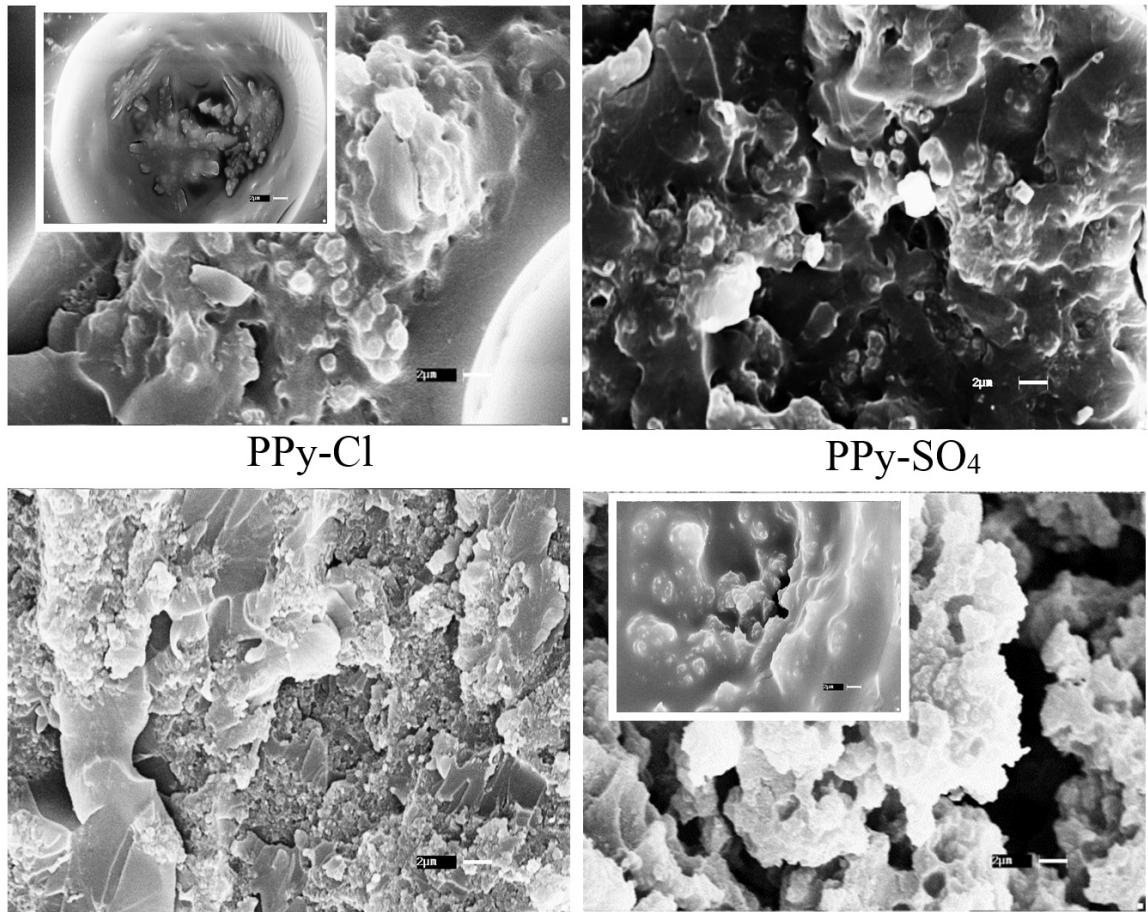

PPy-Cl-DBSNa
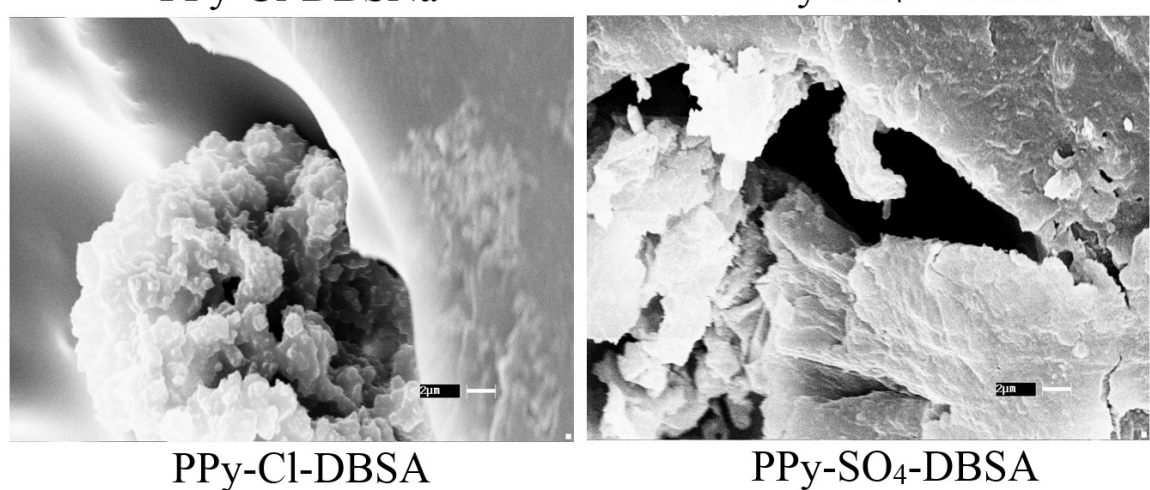

Figure 5. SEM images of the blends with $20 \%(w t / w t)$ of PPy in epoxy resin (3000x)

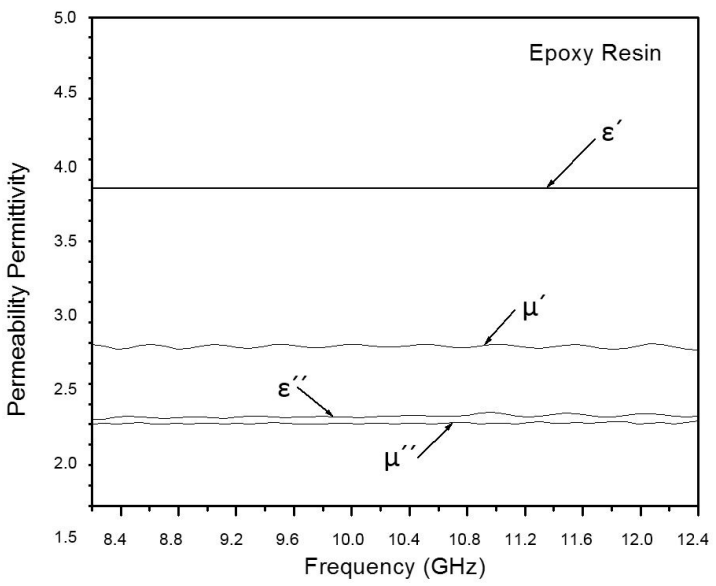

Figure 6. Complex values of electric permittivity $(\varepsilon)$ and magnetic permeability $(\mu)$ as function of frequency of epoxy resin.
Table 2. Values of complex parameters of electric permittivity of epoxy resin and the blends with $20 \%$ (wt/wt) of PPy, at $10 \mathrm{GHz}$.

\begin{tabular}{|c|c|c|}
\hline Sample & $\varepsilon^{\prime}$ & $\varepsilon^{\prime \prime}$ \\
\hline Epoxy resin & 2.7506 & 0.0941 \\
\hline PPy-Cl-20\%/epoxy resin & 6.1410 & 2.1861 \\
\hline PPy-Cl-DBSA20\%/epoxy resin & 3.4650 & 0.5530 \\
\hline PPy-Cl-DBSNa20\%/epoxy resin & 9.4384 & 2.6441 \\
\hline $\mathrm{PPy}_{-} \mathrm{SO}_{4}-20 \% /$ epoxy resin & 3.6339 & 0.5835 \\
\hline $\mathrm{PPy}_{-} \mathrm{SO}_{4}-\mathrm{DBSA} 20 \% /$ epoxy resin & 4.4789 & 1.0023 \\
\hline $\mathrm{PPy} \mathrm{SO}_{4}$-DBSNa20\%/epoxy resin & 8.1288 & 1.9301 \\
\hline
\end{tabular}

of the complex parameter of the blend. Therefore, PPy was not undoped during the preparation of the blends, as these samples show values of real and imaginary components of the electric permittivity higher than those measured for the net epoxy resin (without the addition of PPy). 

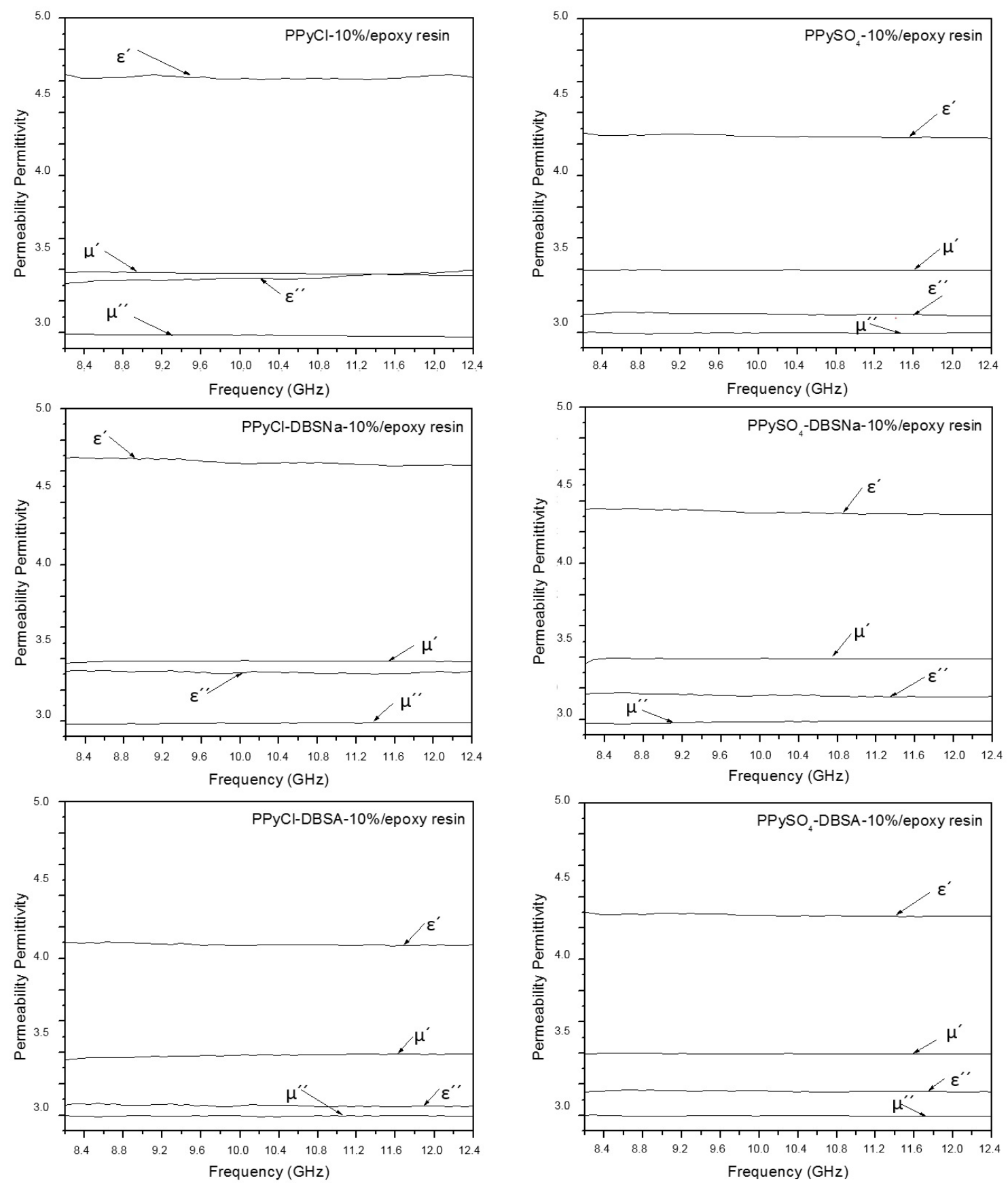

Figure 7. Complex values of electric permittivity $(\varepsilon)$ and magnetic permeability $(\mu)$ as function of the frequency of the blends containing $10 \%(\mathrm{wt} / \mathrm{wt})$ of PPy in epoxy resin.

The analysis of results for the blends with 10 and $20 \%$ (wt/wt) of PPy-Cl-DBSA in the epoxy resin shows that these samples exhibit anomalous behavior, in both Table 1 and Table 2. This suggests that the synthesis of this PPy sample may have suffered some interference and was disregarded in our analysis.

The correlation of the electrical conductivity values, where the blends behave as insulating materials ( $\sigma$ approximately zero), with the data from complex parameters of electric permittivity shown in Tables 1 and 2, it is possible to affirm that the prepared blends have losses mostly by dynamic conductivity ( $\left.\omega \varepsilon^{\prime \prime}\right)$, as shown in Equation 1. This result is consistent with the morphologies observed in Figures 1,3, and 4, in which fractured surfaces consist of distributed clusters of PPy particles isolated by amorphous regions of epoxy resin. These characteristics result in behavior of an insulating material, even though electrically conductive particles were added, as shown in literature ${ }^{[10]}$. 

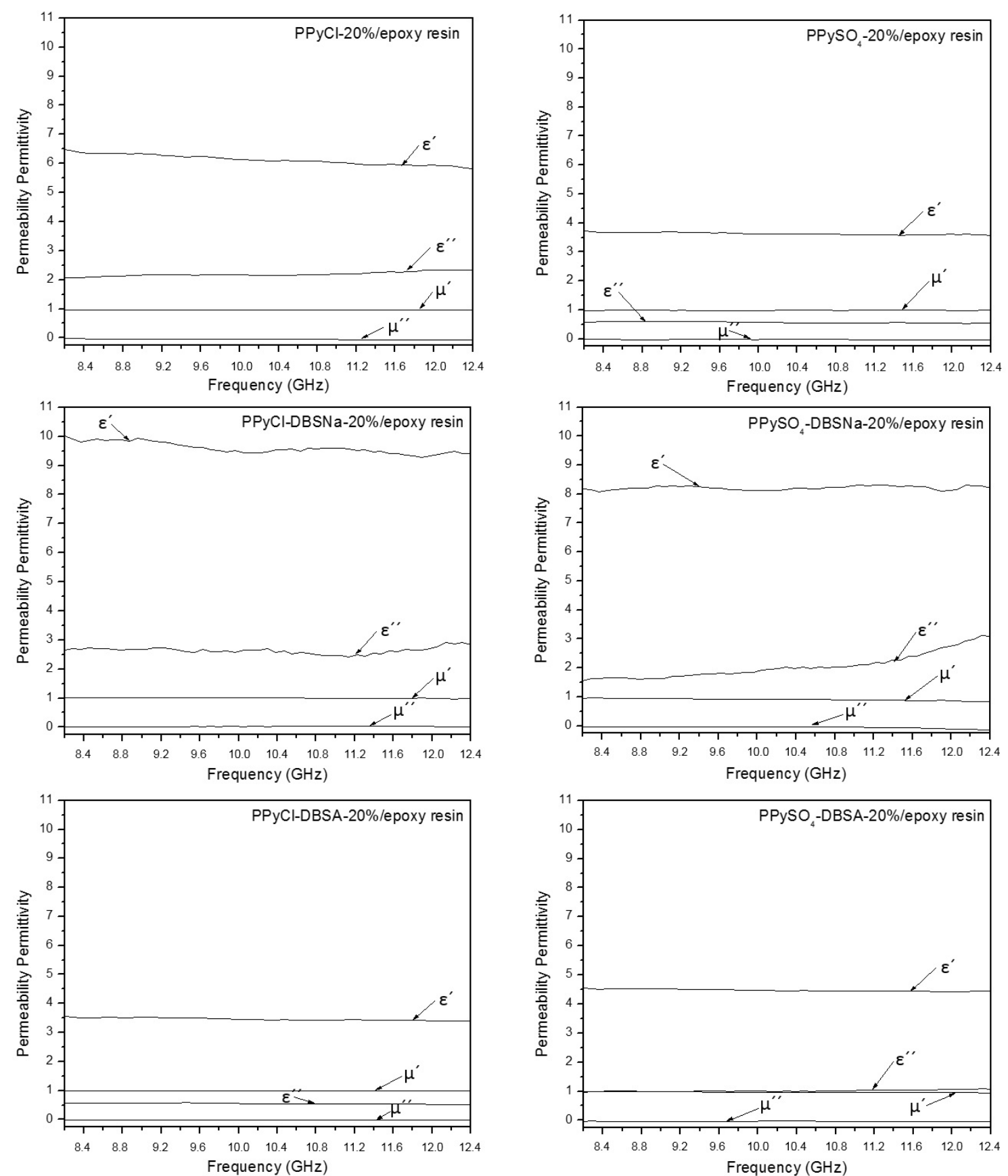

Figure 8. Complex values of electric permittivity $(\varepsilon)$ and magnetic permeability $(\mu)$ as function of the blends containing $20 \%$ (wt/wt) of PPy in epoxy resin.

The correlation of morphological aspects observed in Figures 1, 3, and 4 with the permittivity data presented in Table 2 allows also to conclude that the DBSNa surfactant is what favored the production of the most promising PPy samples for RAM processing. In this case, the texture of clusters, which consist of spherical particles of smaller sizes (Figure 1: $\mathrm{PPy}-\mathrm{Cl}-\mathrm{DBSNa}$ and $\mathrm{PPy}-\mathrm{SO}_{4}-\mathrm{DBSNa}$ ), favors getting the best values of complex parameters. Despite the presence of the fillets in the net PPy samples, which favor the electrical conductivity, as shown in the literature ${ }^{[10]}$.
This study shows that this type of structure does not help increase complex parameters of $\varepsilon$ in the samples blended with the epoxy resin.

\section{Conclusions}

This study involves polypyrrole polymer blends with epoxy resin, using PPy obtained with two different oxidants $\left(\mathrm{Fe}_{2}\left(\mathrm{SO}_{4}\right)_{3}\right.$ and $\mathrm{FeCl}_{3} \cdot 6 \mathrm{H}_{2} \mathrm{O}$ ) and two surfactants (DBSNa and DBSA), respectively. Scanning electron microscopy evidenced that 
the synthesis of PPy in the presence of surfactants decreased the diameter of the particles, and the use of oxidizing sulfate favored the formation of elongated structures, called fillets. The presence of these elongated structures is attributed to steric hindrance of bulky sulfate group in combination with the surfactants, which favored the formation of cylindrical micelles. Although the literature shows that similar samples of PPy are conductive, this study reports that these polymer blends with epoxy resin are insulators. This behavior is attributed to the formation of clusters in the blends, which do not allow the percolation limit to be reached. Measurements of the complex parameters of electric permittivity show that the blends with 10 and $20 \%$ (wt/wt) of PPy have increasing values of these parameters with increased concentration of the conductive polymer in the epoxy resin. In this case, the most promising data were obtained for blends containing $20 \%(\mathrm{wt} / \mathrm{wt})$ of PPy-Cl-DBSNa and $\mathrm{PPy}_{-} \mathrm{SO}_{4}-\mathrm{DBSNa}$ $\left(\varepsilon^{\prime}=9.4384\right.$ and 8.1288 , and $\varepsilon "=2.6441$ and 1.9301 , respectively), evidencing the positive effect of DBSNa surfactant in the synthesis of PPy. The correlation of the data obtained in this study with results in the literature, for the same samples, shows that the losses of electromagnetic radiation for the studied blends are dominated by the dynamic conductivity ( $\omega \varepsilon ")$ and not by ohmic losses (conductivity by four points).

\section{Acknowledgements}

The authors thank CNPq for the financial support (Processes 142314/2010-2 and 303287/2013-6), CAPES/PVNS and the Materials Division of Institute of Aeronautics and Space.

\section{References}

1. Santos, M. J. L., Brolo, A. G., \& Girotto, E. M. (2007). Study of polaron and bipolaron states in polypyrrole by in situ Raman spectroelectrochemistry. Electrochimica Acta, 52(20), 61416145. http://dx.doi.org/10.1016/j.electacta.2007.03.070.

2. MacDiarmid, A. G., \& Maxfield, M. (1987). Organic polymers as electroactive materials. Electrochemical Science and Technology of Polymers, 1, 67-102. http://dx.doi.org/10.1007/978-94-0093413-9_4.

3. Diaz, A. F., Castillo, J. I., Logan, J. A., \& Lee, W. Y. (1981). Electrochemistry of conducting polypyrrole films. Journal of Electroanalytical Chemistry and Interfacial Electrochemistry, 129(1-2), 115-132. http://dx.doi.org/10.1016/S00220728(81)80008-3.

4. Zoppi, R. A., \& De Paoli, M.-A. (1996). Chemical preparation of conductive elastomeric blends: polypyrrole/EPDM-II: utilization of matrices containing crosslinking agents, reinforcement fillers and stabilizers. Polymer, 37(10), 1999-2009. http:// dx.doi.org/10.1016/0032-3861(96)87318-6.

5. Faez, R., Martin, I. M., Rezende, M. C., \& De Paoli, M.-A. (2001). Acompanhamento do processamento de elastômeros condutores por microscopia eletrônica de varredura. Polímeros: Ciência e Tecnologia, 11(3), 121-125. http://dx.doi.org/10.1590/ S0104-14282001000300011.

6. Jonas, F., \& Morrison, T. (1997). 3,4-Polyethylenedioxythiophene (PEDT): conductive coatings technical apllications and properties. Synthetic Metals, 85(1-3), 1397-1398. http://dx.doi. org/10.1016/S0379-6779(97)80290-1.

7. Biscaro, R. S., Rezende, M. C., \& Faez, R. (2008). Influence of doped polyaniline on the interaction of $\mathrm{Pu} / \mathrm{PAni}$ blends and on its microwave absorption properties. Polymers for Advanced Technologies, 19(2), 151-158. http://dx.doi.org/10.1002/pat.990.

8. Folgueras, L. C., Alves, M. A., \& Rezende, M. C. (2010). Dielectric properties of microwave absorbing sheets produced with silicone and polyaniline. Materials Research, 13(2), 197201. http://dx.doi.org/10.1590/S1516-14392010000200013.

9. Folgueras, L. C., Alves, M. A., \& Rezende, M. C. (2010). Microwave absorbing paints and sheets based on carbonyl iron and polyaniline: measurement and simulation of their properties. Journal of Aerospace Technology and Management, 2(1), 63-70. http://dx.doi.org/10.5028/jatm.2010.02016370.

10. Campos, R. A. M., Faez, R., \& Rezende, M. C. (2014). Síntese do polipirrol com surfactantes aniônicos visando aplicações como absorvedores de micro-ondas. Polímeros: Ciência e Tecnologia, 24(3), 351-359.

11. Panigrahi, R., \& Srivastava, S. K. (2015). Trapping of microwave radiation in hollow polypyrrole microsphere through enhanced internal reflection: a novel approach. Scientific Reports, 5, 76387643. http://dx.doi.org/10.1038/srep07638. PMid:25560384.

12. Hosseini, S. H., \& Asadnia, A. (2012). Synthesis, characterization, and microwave-absorbing properties of polypyrrole/ $\mathrm{MnFe} 2 \mathrm{O} 4$ nanocomposite. Journal of Nanomaterials, 2012, 1-6. http:// dx.doi.org/10.1155/2012/198973.

13. Bhavsar, V., \& Tripathi, D. (2014). Complex permittivity and microwave absorption studies of polypyrrole doped polyvinylchloride films. Advance in Electronic and Electric Engineering, 4(4), 417-424

14. Chakraborty, H., Chabri, S., \& Bhowmik, N. (2013). Electromagnetic interference reflectivity of nanostructured manganese ferrite reinforced polypyrrole composites. Transactions on Elextrical and Electronics Materials, 14(6), 295-298. http://dx.doi.org/10.4313/TEEM.2013.14.6.295.

15. Zoppi, R. A., \& De Paoli, M.-A. (1995). Elastômeros condutores derivados de polipirrol e borracha de EPDM: preparação e propriedades. Polímeros: Ciência e Tecnologia, 5(3), 19-31.

16. Olmedo, L., Houquerbie, P., \& Jousse, F. (1997). Handbook of organic conductive molecules and polymers. New York: John-Wiley.

17. Girotto, E. M., \& Santos, I. A. (2002). Medidas de resistividade elétrica dc em sólidos: como efetuá-las corretamente. Quimica Nova, 25(4), 639-647. http://dx.doi.org/10.1590/S010040422002000400019 .

18. Agilent Technologies. (2005). Materials measurement software Agilent. Califórnia: Agilent Technologies.

19. Agilent Technologies. (2007). Waveguide calibration in network analysis: accuracy enhancement. Califórnia: Agilent Technologies.

20. Pereira, J. J. (2007). Caracterização eletromagnética de materiais absorvedores de microondas via medidas de permissividade e permeabilidade complexas na banda X (Master's dissertation). Universidade de Taubaté, Taubaté.

21. Oliveira, S. R. (2006). Interação de ácido algínico com surfactantes catiônicos em solução aquosa (Doctoral thesis). Universidade Estadual Paulista "Júlio de Mesquita Filho", São José do Rio Preto.

22. Su, S.-J., \& Kuramoto, N. (2000). Synthesis of processable polyaniline complexed with anionic surfactant and its conducting blends in aqueous and organic system. Synthetic Metals, 108(2), 121-126. http://dx.doi.org/10.1016/S0379-6779(99)00185-X.

23. Kim, J., Kwon, S., \& Ihm, D. (2007). Synthesis and characterization of organic soluble polyaniline prepared by one-step emulsion polymerization. Current Applied Physics, 7(2), 205-206. http:// dx.doi.org/10.1016/j.cap.2006.05.001.

24. Abdiryim, T., Jamal, R., \& Nurulla, I. (2007). Doping effect of organic sulphonic acids on the solid-state synthesized 
Campos, R. A. M., Silva, V. A., Faez, R., \& Rezende, M. C.

polyaniline. Journal of Applied Polymer Science, 105(2), 576-584. http://dx.doi.org/10.1002/app.26070.

25. Balanis, C. A. (2005). Advanced engineering electromagnetic. New York: John-Wiley.

26. Pozar, D. M. (2005). Microwave engineering. New York: John-Wiley.

27. Silva, S. M. L., Rezende, M. C., \& Faro, A. J. O. Design of multilayer dielectric absorber material of microwave based on properties and interactions with signals of high frequency: one route of experimental analysis. Journal of Materials Research. In press.

Received: Mar. 30, 2015

Revised: Dec. 15, 2015

Accepted: May 23, 2016 